\title{
SIMULATION OF INFLUENCE OF THE TRAFFIC NETWORK UPON THE ENVIRONMENT WITHIN THE TECHNOLOGICALLY LOADED ECOSYSTEM
}

\author{
PernebeKov, S. S. ${ }^{1 *}$ - Ussipbayev, U. A. ${ }^{1}$ - Tortbayeva, D. R. ${ }^{1}$ - GAISINA, G. A. ${ }^{2}-$ \\ FARRAKHOVA, F. F. ${ }^{3}$ \\ ${ }^{I}$ Department of Transport, Organization of Transport and Traffic, M. Auezov South Kazakhstan \\ State University, 5 Taukekhan Ave., 160012 Shymkent, Republic of Kazakhstan \\ ${ }^{2}$ Department of Heat Power Engineering and Physics, Bashkir State Agrarian University, 34 \\ 50th Anniversary of October Str., 450001 Ufa, Republic of Bashkortostan, Russian Federation \\ ${ }^{3}$ Department of Accounting, Statistics and Information Systems in Economics, Bashkir State \\ Agrarian University, 34 50th Anniversary of October Str., 450001 Ufa, Republic of \\ Bashkortostan, Russian Federation \\ *Corresponding author \\ e-mail: saken_uko@mail.ru; phone: +8-701-727-4587 \\ (Received $7^{\text {th }}$ Dec 2018; accepted $4^{\text {th }}$ Feb 2019)
}

\begin{abstract}
Traffic networks within megapolises is the factor of acceleration and modernisation of the socio-economic environment. However, there exist a number of problems, which restrict the possibilities of development of a city transport medium. Particularly, road design will only begin when the living environment of urban residents is completed. In this case, formation of the road network and making decisions in respect of its modernisation are performed in accordance with the actual workload of the city network. Authors of this article state that such planning is an inconsistent process, because it cannot predict the decline of the socio-economic environment. The article expressly demonstrates that use of traditional parameters in respect of quality of design of a road network does not comply with the modern requirements to the quality of the socio-economic environment, which must be in line with the already designed road network. Authors of this article believe that it is absolutely necessary to have clear definitions of those criteria, which will be universal ones for design and management of the road network within a modern megapolis. As concerns possible solution of this problem, authors of this article propose to use ecological indicators, as well as content of toxic elements and motor vehicle emissions near the road network.
\end{abstract}

Keywords: road network, management, loaded system, socio-economic environment, simulation methods

\section{Introduction}

Influence of the motor transport upon the ecological situation in Republic of Kazakhstan has achieved a critical limit already. Various environmental pollution sources exist, however motor vehicle systems (motor roads and motor vehicles) are the most dangerous ones. Analysis of the previous experience of ecological investigations in the road traffic sphere demonstrates that in many cases these investigations are performed separately for traffic flows and motor roads (Goniewicz et al., 2016). Environmentally destructive influence of the motor vehicle systems is widespread one due to the great mileage and branching of the motor road network, as well as due to high mobility of traffic flows along with the ever-growing quantity of the transportation facilities (Duduta, 2015; Ghahramani and Hemmatyar, 2017). Scales of contamination of the environment are also under the influence of irregularity of motor vehicle traffic 
flows within the cities, particularly in the places of delays before traffic lights and in the cases of road traffic congestions on the motor roads.

The aim of this investigation is the performance of ecological monitoring in the urban agglomerations to develop the relevant methods to decrease harmful influence of transport upon the environment with the help of the proper strict organisation of the road traffic. The presented research will help to ensure a sufficient level of ecological safety in the urban agglomerations, as well as determine the priority and volume of the environmental protection measures and provision of the ecological monitoring points with software applications, organisation and technical means and facilities for performance of such monitoring. Scientific novelty of the work: a general method has been developed for the integrated assessment of the technogenic impact of a roadtransport complex on an ecosystem that considers the state of the ecosystem taking into account all the essential components of the object of study and the relationship between them in the "driver-car-road-environment" system; a number of indicators characterizing the impact of road transport on the environment were identified; the factors and spatial features of the impact of road transport on the environment were identified.

The results of the study can be applied in justification of targeted regional environmental and economic programs aimed at improving the ecological status of the region; in the study of the interaction of road transport systems and the environment in other regions and countries.

\section{Materials and methods}

Depending on the goal of an investigation, various methods can be used in order to define the road traffic characteristics: documentary methods, natural full-scale methods, as well as simulation methods (Goniewicz et al., 2016).

Documentary methods are based on the study and analysis of the planning, reporting, statistical materials, as well as design-and-technical materials. In addition, this group of methods includes questionnaire surveys in respect of the traffic flows and passenger flows. Such documentary methods use dependences between traffic volumes and volumes of production, density of population within traffic areas, travel behaviour of population etc. As a rule, these documentary methods are characterized as the labourintensive techniques, which ensure low accuracy of final results (Kureckova, 2017). Methods of the natural full-scale surveys are based on the performance of direct measurements of the road traffic characteristics in various investigative areas. It is possible to obtain proper information with the help of direct observations or with the help of the automatic registration facilities (Chang et al., 2014).

Such natural full-scale surveys include local, zonal, and regional surveys. Local surveys are performed in order to study intensities, speeds, and composition of flows at the road intersections, as well as at certain sections of roads and streets (Chang, 2011).

Zonal surveys are performed in order to obtain spatial and temporal characteristics within a certain zone. These surveys are performed as the sample surveys. Regional surveys are performed in order to obtain summary values of parameters of traffic flows within a district, city, and region. These parameters are used for predicting trends of changes in the flow characteristics in the course of construction and reconstruction of objects. Advantages of methods of the natural full-scale surveys are connected with their simplicity and high accuracy. Their disadvantages are connected with high labour- 
intensity of these surveys, as well as with the impossibility of utilisation of these methods for the objects that were designed earlier.

In addition, methods of simulation are often used. These methods are based on the use of mathematical and nonmathematical models (physical and analogous models) of changes of the traffic flow parameters. For example, main equation of the transportation flow is derived from the mathematical model, which describes interconnection between intensity, speed, and density of the traffic flow. Simulation methods ensure lower accuracy as compared with the methods of the natural full-scale surveys. However, these methods are simple in the course of their utilisation and they do not require engagement of many recorders. In addition, simulation methods can be applied for the already designed objects (Svensson et al., 2014).

In order to perform investigations of ecosystems, it is necessary to estimate physical level of emissions, degree of influence of motor vehicle flows upon the environment in the specific conditions of certain cities, as well as to define the most essential factors. These estimations and definitions must be made in accordance with the results of the natural full-scale observations (Marisamynathan and Vedagiri, 2018).

These investigations were performed on the basis of the reports on organisation of the traffic scheme of the transportation facilities within a city and its surroundings, as well as on the basis of the results of observations in respect of levels of physical and chemical pollution of the atmospheric air. Experimental investigations have been included the following areas for collection of the initial material: results of measurements of the meteorological data at the regime observation points; information on the nature of the transport and passenger flows; disposition of routes in respect of various tracks, scheme of their disposition on the city map; traffic charts over various routes.

To study the complex dependence of concentration of the summary emissions of the nitrogen dioxide, carbon oxides, sulphur dioxide, and hydrocarbons, the quantity and type of the motor vehicles passing through the relevant road intersection (Fig. 1, Shymkent, Republic of Kazakhstan) were calculated. And the multiple-factor correlation-and-regression analysis was used.

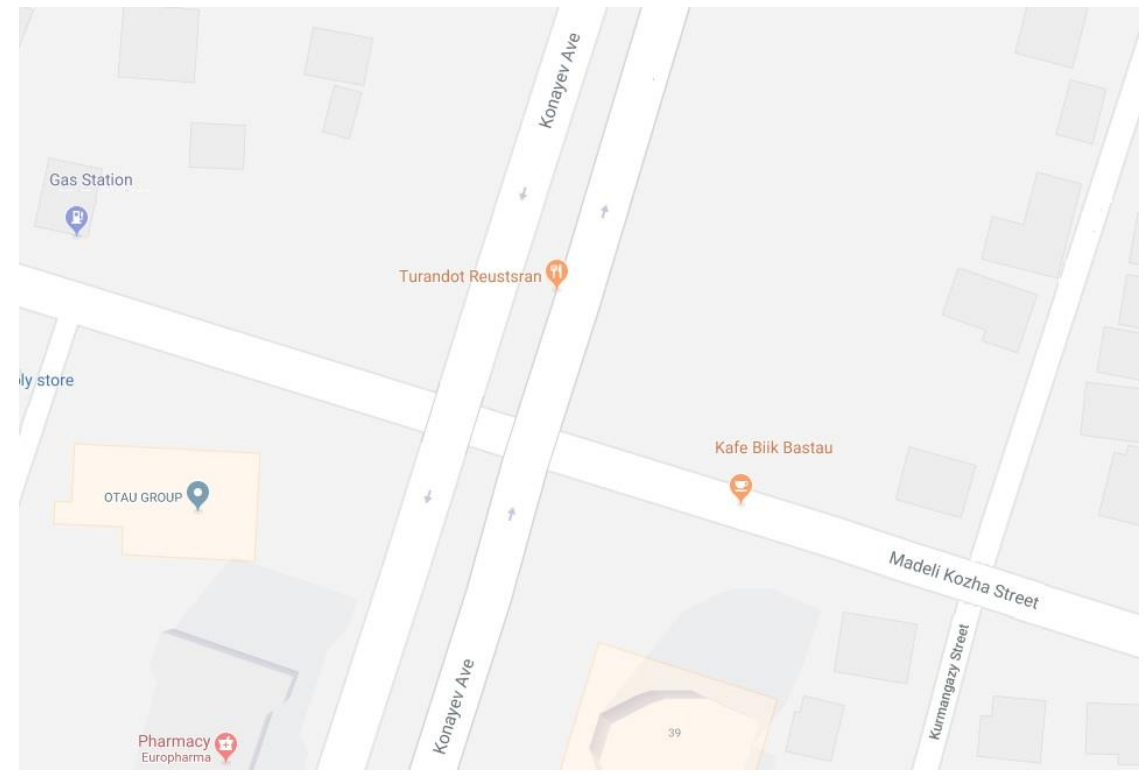

Figure 1. Investigated road intersection (Shymkent, Republic of Kazakhstan) 
In order to define characteristics of the motor vehicle flows in respect of the selected section of the certain street-and-road network, the following groups of motor vehicles were recorded (these vehicles moved in both directions):

- Gasoline-powered passenger cars (GPPC);

- Diesel-powered passenger cars (DPPC);

- Gasoline-powered lorries (GPL);

- Diesel-powered lorries (DPL);

- Gasoline-powered buses (GPB);

- Diesel-powered buses (DPB).

Calculation of the transportation facilities, which have been gone through the relevant road intersection, has been performed during $20 \mathrm{~min}$ on an hourly basis. In the cases of high traffic intensity (more than 2-3 thousand motor vehicles per hour), calculation of motor vehicles has been performed synchronously and separately in respect of each direction of traffic.

In order to define the maximum traffic load, observations have been performed during peak hours. Two maximums were assumed for the relevant road intersection: morning and evening maximums (7-11 a.m. and 4-7 p.m. respectively). In accordance with the results of this experimental investigation, which are presented in Table 1.

Table 1. Experimental results of the investigation with the purpose to define content of the polluting substances in the atmospheric air at the section 1 in 2017

\begin{tabular}{c|c|c|c|c|c|c|c|c|c|c|c}
\hline Month & $\begin{array}{c}\text { DPPC, } \\
\text { pcs. }\end{array}$ & $\begin{array}{c}\text { GPPC, } \\
\text { pcs. }\end{array}$ & $\begin{array}{c}\text { DPL, } \\
\text { pcs. }\end{array}$ & $\begin{array}{c}\text { GPL, } \\
\text { pcs. }\end{array}$ & $\begin{array}{c}\text { GPB, } \\
\text { pcs. }\end{array}$ & $\begin{array}{c}\text { DPB, } \\
\text { pcs. }\end{array}$ & $\begin{array}{c}\text { Total, } \\
\text { pcs. }\end{array}$ & $\begin{array}{c}\mathbf{C O}, \\
\mathbf{m g} / \mathbf{m}^{3}\end{array}$ & $\begin{array}{c}\mathbf{N O}_{2} \\
\mathbf{m g} / \mathbf{m}^{3}\end{array}$ & $\begin{array}{c}\mathbf{C H} \\
\mathbf{m g} / \mathbf{m}^{3}\end{array}$ & $\begin{array}{c}\mathbf{S O}_{2} \\
\mathbf{m g} / \mathbf{m}^{3}\end{array}$ \\
\hline 1 & 218.952 & 246.929 & 57.431 & 26.742 & 251.967 & 125.975 & 927.996 & 3.13 & 0.09 & 0.025 & 0.026 \\
2 & 326.562 & 312.786 & 84.329 & 54.285 & 311.734 & 216.853 & $1,306.549$ & 4.4 & 0.12 & 0.03 & 0.031 \\
3 & 339.567 & 324.128 & 87.532 & 58.621 & 362.749 & 239.524 & $1,412,121$ & 4.9 & 0.136 & 0.04 & 0.032 \\
4 & 336.873 & 368.354 & 83.218 & 54.671 & 372.961 & 218.496 & $1,434,573$ & 5.1 & 0.14 & 0.039 & 0.031 \\
5 & 367.561 & 389.572 & 71.643 & 41.866 & 343.451 & 206.781 & $1,420.874$ & 5.4 & 0.126 & 0.039 & 0.031 \\
6 & 332.986 & 378.612 & 75.328 & 37.549 & 327.693 & 198.669 & $1,350.837$ & 4.76 & 0.114 & 0.037 & 0.03 \\
7 & 298.456 & 369.532 & 67.589 & 26.431 & 263.651 & 177.533 & $1,203,192$ & 4.6 & 0.102 & 0.027 & 0.02 \\
8 & 321.568 & 384.523 & 74.873 & 32.187 & 311.678 & 185.462 & $1,310,291$ & 5.07 & 0.113 & 0.03 & 0.028 \\
9 & 373.467 & 386.673 & 79.003 & 42.622 & 312.621 & 226.548 & $1,420.934$ & 6 & 0.13 & 0.04 & 0.029 \\
10 & 327.855 & 371.220 & 70.455 & 39.781 & 366.720 & 194.331 & $1,370,362$ & 5.46 & 0.12 & 0.033 & 0.031 \\
11 & 341.879 & 322.853 & 78.451 & 51.439 & 344.112 & 223.471 & $1,362,205$ & 4.62 & 0.128 & 0.035 & 0.031 \\
12 & 210.547 & 223.731 & 40.571 & 22.760 & 237.622 & 103.651 & 838,882 & 2.4 & 0.071 & 0.018 & 0.023 \\
\hline
\end{tabular}

\section{Results and discussion}

\section{Multiple-factor correlation-and-regression analysis}

In order to investigate complex dependence of concentration of the summary emissions of the nitrogen dioxide (Fig. 2), carbon oxides (Fig. 3), sulphur dioxide (Fig. 4), and hydrocarbons (Fig. 5) from the quantity and type of the motor vehicles, which have gone through the relevant road intersection, we will use the multiple-factor correlation-and-regression analysis. This kind of analysis will make it possible to estimate degree of influence of each parameter upon concentration of the exhaust gases provided that average level of other parameters is fixed. In this case, the following 
condition is important: absence of any functional relationships between these parameters.

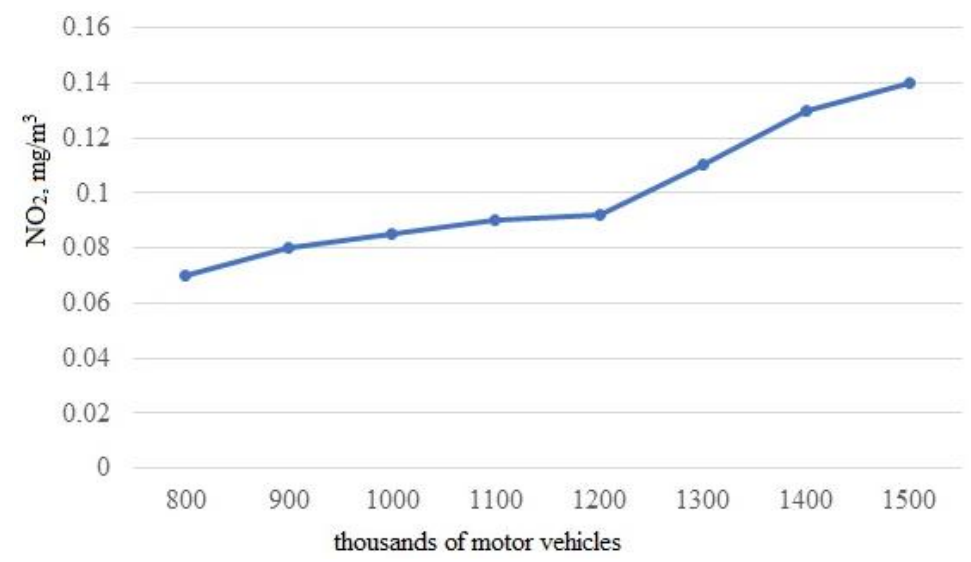

Figure 2. Graphical dependence of the nitrogen dioxides concentration from quantity of motor vehicles at the experimental area 1 in 2017

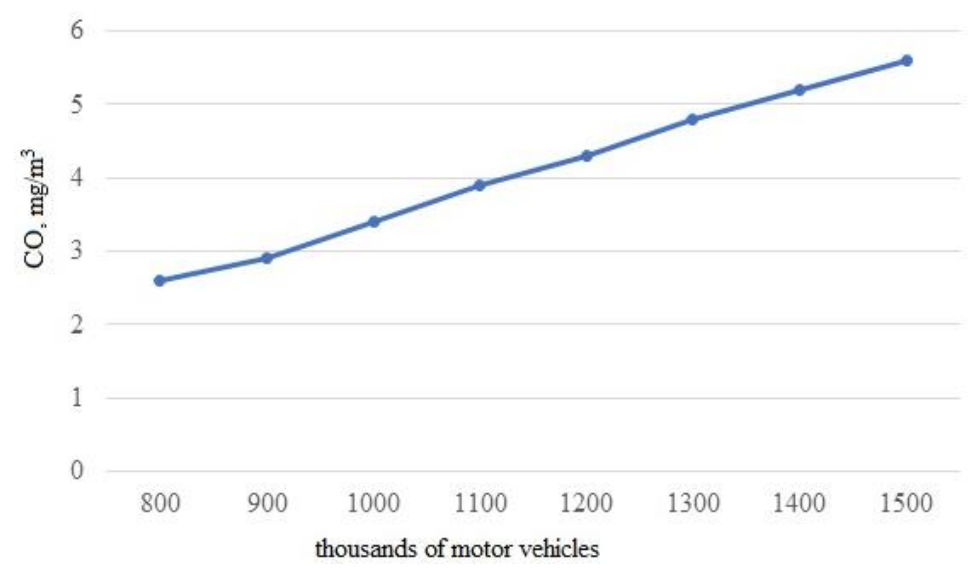

Figure 3. Graphical dependence of the carbon oxides concentration from quantity of motor vehicles at the experimental area 1 in 2017

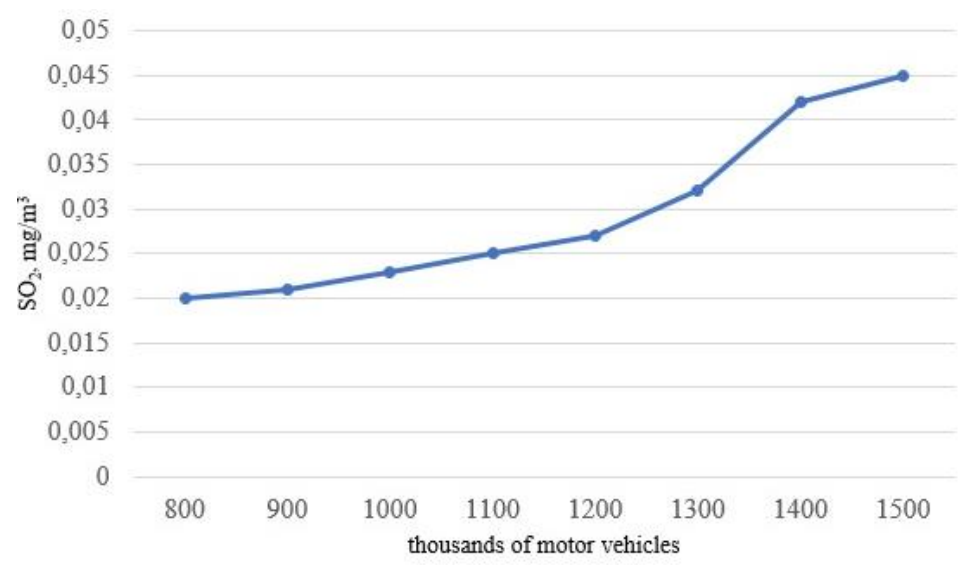

Figure 4. Graphical dependence of the sulphur dioxides concentration from quantity of motor vehicles at the experimental area 1 in 2017 


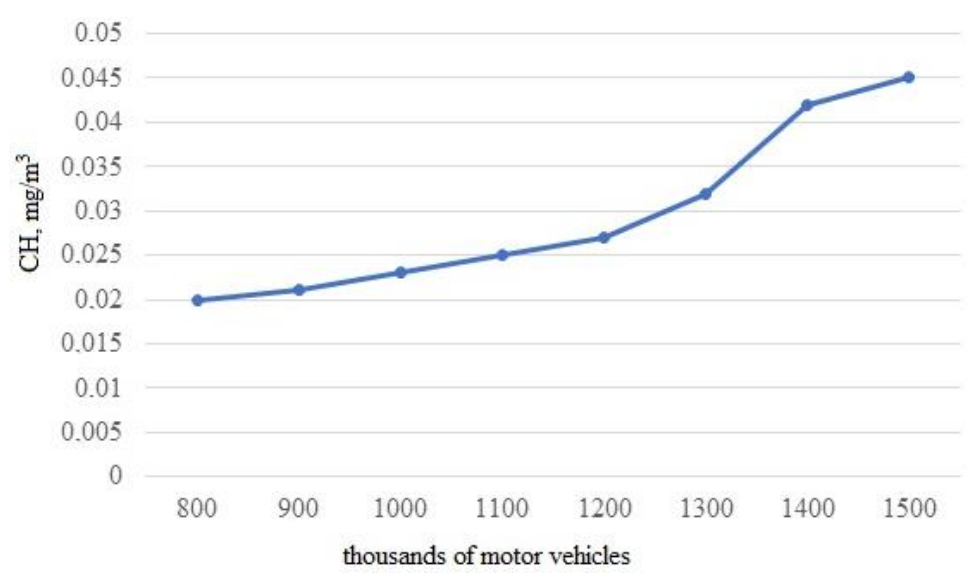

Figure 5. Graphical dependence of the hydrocarbon concentration from quantity of motor vehicles at the experimental area 1 in 2017

From a mathematical standpoint, the problem reduces to finding the analytic expression, which would describe relationships of the factorial characteristics with the resulting characteristics in the best way possible, that is, we have to find the following function $(E q .1)$ :

$$
y=f\left(x_{1} \cdot x_{2}, \ldots, x_{p}, a_{0}, a_{1}, \ldots, a_{p}\right)
$$

where $a_{0}, a_{1}, \ldots, a_{p}$ are coefficients of the regression equation, which would ensure the least scatter of empirical values in respect of the surface, which is described by this function.

The most difficult problem is connected with selection of the form of interconnection, selection of the analytic expression. On the basis of this selection, it is possible to define the resulting characteristic, that is, the function, which is connected with the existing factors. This mass function describes actual interconnections between the parameter to be investigated and other relevant factors better than other possible functions. The empirical substantiation of the function type with the help of the graphical analysis of the interconnections for the multiple-factor models is almost impractical. Therefore, it is possible to define proper form of interconnection through the fitting of functions of various types, but it is connected with the great quantity of the unnecessary calculations. Despite of the fact that it is possible to transform any function of multiple variables (through logarithmation or with the help of replacement of variables) to the linear form, it is also possible to present a multiple regression equation in the linear form as follows (Eq. 2):

$$
y=a_{0}+a_{1} x_{1}+a_{2} x_{2}+a_{3} x_{3}+\ldots+a_{n} x_{n}
$$

In our case, we will assume concentrations of the relevant exhaust gases as the resulting characteristics. In addition, we will assume quantities of the relevant motor vehicles as the factorial characteristics. Therefore, the sought-for equation of the linear six-factorial regression will be presented in the following form (Eq. 3): 


$$
y=a_{0}+a_{1} x_{1}+a_{2} x_{2}+a_{3} x_{3}+a_{4} x_{4}+a_{5} x_{5}+a_{6} x_{6}
$$

where $y$ are calculated values of the resulting characteristics - functions (in our case), that is, concentrations of the exhaust gases; $\mathrm{x}_{1}, \mathrm{x}_{2}, \mathrm{x}_{3}, \mathrm{x}_{4}, \mathrm{x}_{5}, \mathrm{x}_{6}$ are factorial characteristics on the condition that: $\mathrm{x}_{1}$ is the quantity of the gasoline-powered passenger cars; $\mathrm{x}_{2}$ is the quantity of the diesel-powered passenger cars; $\mathrm{x}_{3}$ is the quantity of the gasoline-powered lorries; $\mathrm{x}_{4}$ is the quantity of the diesel-powered lorries; $\mathrm{x}_{5}$ is the quantity of the gasoline-powered buses; $\mathrm{x}_{6}$ is the quantity of the diesel-powered buses; $\mathrm{a}_{0}, \mathrm{a}_{1}, \mathrm{a}_{2}, \mathrm{a}_{3}, \mathrm{a}_{4}, \mathrm{a}_{5}, \mathrm{a}_{6}$ are equation parameters, which are calculated in accordance with the least square method. Therefore, it is necessary to solve the system of normal equations (Eq. 4):

$$
\left\{\begin{array}{c}
n a_{0}+a_{1} \sum x_{1}+a_{2} \sum x_{2}+a_{3} \sum x_{3}+a_{4} \sum x_{4}+a_{5} \sum x_{5}+a_{6} \sum x_{6}=\sum y \\
a_{0} \sum x_{1}+a_{1} \sum x_{1}^{2}+a_{2} \sum x_{1} x_{1}+a_{3} \sum x_{1} x_{3}+a_{4} \sum x_{1} x_{1}+a_{5} \sum x_{1} x_{5}+a_{6} \sum x_{1} x_{6}=\sum x_{1} y \\
a_{0} \sum x_{2}+a_{1} \sum x_{1} x_{2}+a_{2} \sum x_{2}+a_{3} \sum x_{2} x_{3}+a_{4} \sum x_{4} x_{4}+a_{5} \sum x_{2} x_{5}+a_{6} \sum x_{2} x_{6}=\sum x_{2} y \\
a_{0} \sum x_{3}+a_{1} \sum x_{1} x_{3}+a_{2} \sum x_{2} x_{3}+a_{3} \sum x_{3}^{2}+a_{4} \sum x_{3} x_{4}+a_{5} \sum x_{3} x_{5}+a_{6} \sum x_{3} x_{6}=\sum x_{3} y \\
a_{0} \sum x_{4}+a_{1} \sum x_{1} x_{4}+a_{2} \sum x_{2} x_{4}+a_{3} \sum x_{3} x_{4}+a_{4} \sum x_{4}^{2}+a_{5} \sum x_{4} x_{5}+a_{6} \sum x_{4} x_{6}=\sum x_{4} y \\
a_{0} \sum x_{5}+a_{1} \sum x_{1} x_{5}+a_{2} \sum x_{2} x_{5}+a_{3} \sum x_{3} x_{5}+a_{4} \sum x_{4} x_{5}+a_{5} \sum x_{5}^{2}+a_{6} \sum x_{5} x_{6}=\sum x_{5} y \\
a_{0} \sum x_{6}+a_{1} \sum x_{1} x_{6}+a_{2} \sum x_{2} x_{6}+a_{3} \sum x_{3} x_{6}+a_{4} \sum x_{4} x_{6}+a_{5} \sum x_{5} x_{6}+a_{6} \sum x_{6}^{2}=\sum x_{6} y
\end{array}\right.
$$

Each coefficient of this equation determines degree of influence of the relevant factor upon the resulting parameter on the condition of the fixed values of the rest factors, that is, each coefficient determines degree of change of the resulting parameter in the case of change of a certain factor by one unit. The sample correlation coefficient and sample estimates $a_{0}, a_{1}, a_{2}, a_{3}, a_{4}, a_{5}, a_{6}$ of the regression parameters (which were calculated on the basis of the restricted quantity of the experimental data) always contain elements of randomness, and they themselves are random values in essence. In this connection, there occurs a necessity to check meaningfulness of these sample characteristics.

The criterion for testing adequacy of the regression function envisages testing of meaningfulness of the multiple correlation coefficient R. In this connection, the hypothesis "H0: $\mathrm{R} 2=0$ " is proposed in respect of the fact that coefficient of determination $\mathrm{R}^{2}$ of the general totality (from which this sample was obtained) is equal to zero. This hypothesis is equally matched with the hypothesis $\mathrm{H}_{0}$ : $a_{0}=a_{1}=a_{2}=a_{3}=a_{4}=a_{5}=a_{6}=0$ in respect of the fact that none of those factors, which were included to this regression, has no essential (meaningful) influence upon the response $y$. Let us consider the hypothesis $\mathrm{H} 1: \mathrm{R}^{2} \neq 0$ as an alternative, that is, situation, when at least one of the regression coefficients $\mathrm{a}_{\mathrm{i}} \neq 0$. The following statistics $(E q .5)$ is used in the course of testing this hypothesis:

$$
F=\frac{R^{2}}{1-R^{2}} \times \frac{n-p}{p-1}
$$

where $n$ is quantity of those observations, on the basis of which value $\mathrm{R}$ has been calculated, while $P$ is quantity of the regression parameters. In addition, in the course of 
testing the hypothesis $\mathrm{H}_{0}$, the right-side critical region $\left.\Omega[f(\alpha ; p-1 ; n-p), \infty)\right]$ is used, where $F_{k p}=f(\alpha ; p-1 ; n-p)$ is the critical value of $\alpha$ order of the Fisher-Snedecor distribution with $(\mathrm{p}-1)$ and $(\mathrm{n}-\mathrm{p})$ degrees of freedom.

Then the right-side critical region is defined by the inequality $\mathrm{f}>\mathrm{F}_{\text {crit, }}$, while acceptance region of the zero hypothesis is defined by the inequality. If the calculated value of the $f$-statistics exceeds its critical value $F_{\text {crit, }}$, that is, $f<F_{\text {crit }}$, then the zero hypothesis $\mathrm{H}_{0}$ is rejected and the alternative hypothesis $\mathrm{H}_{1}$ is assumed. In this case, the coefficient of determination $\mathrm{R}^{2}$ differs from zero essentially, while the regression function is the statistically meaningful function, which describes the original data adequately.

We will estimate degree of influence of those characteristics, which are included in (3), in accordance with the results of testing the hypothesis concerning statistical meaningfulness of the coefficient of the relevant regression equation, which complies with proper characteristics.

With this aim in view, the hypothesis $\mathrm{H}_{0}: \mathrm{a}_{\mathrm{i}}=0$ is proposed in respect of the fact that factor $\mathrm{x}_{\mathrm{i}}$ has no essential influence upon the response $y$. In addition, the hypothesis $\mathrm{H}_{1}$ : $\mathrm{a}_{0} \neq 0$ is proposed as an alternative. In the course of testing of this hypothesis the twosided region $\left(|T| \geq t\left(\frac{\alpha}{2} ; n-p\right)\right)$ is used, where $T=t\left(\frac{\alpha}{2} ; n-p\right)$ is the critical value of the order $\frac{\alpha}{2}$ of the Student distribution with $(\mathrm{n}-\mathrm{p})$ degrees of freedom. If $\mathrm{t}_{\mathrm{i}} \leq \mathrm{T}_{\mathrm{cr}}$, then the hypothesis $\mathrm{H}_{0}: \mathrm{a}_{\mathrm{i}}=0$ is assumed, otherwise it is thought that this coefficient is other than zero.

\section{Concentration of the summary emissions of $\mathrm{NO}_{2}, \mathrm{CO}, \mathrm{SO}_{2}, \mathrm{CH}$}

Taking into account the fact that volume of the data is a comparatively great one in order to find coefficients of the regression equation, it is possible to apply Mathlab application software, because it includes the built-in statistical functions, which make it possible to perform calculations quickly. We will perform these calculations separately for the carbon oxides $(\mathrm{CO})$, nitrogen dioxide $\left(\mathrm{NO}_{2}\right)$, sulphur dioxide $\left(\mathrm{SO}_{2}\right)$, and for the hydrocarbons $(\mathrm{CH})$. Results of these calculations are presented in Table 2.

Table 2. Carbon oxides (CO) (2017)

\begin{tabular}{c|c|c|c|c|c|c}
\hline $3.12524 \cdot 10^{-5}$ & $1.58101 \cdot 10^{-5}$ & -0.000108872 & $1.44834 \cdot 10^{-5}$ & $-1.40348 \cdot 10^{-5}$ & $6.46997 \cdot 10^{-6}$ & 4.141839001 \\
\hline $1.58577 \cdot 10^{-5}$ & $4.87854 \cdot 10^{-6}$ & $3.67525 \cdot 10^{-5}$ & $3.16138 \cdot 10^{-5}$ & $6.99962 \cdot 10^{-6}$ & $9.99331 \cdot 10^{-6}$ & 1.01508043 \\
\hline 0.9542 & 0.241512841 & N/A & N/A & N/A & N/A & N/A \\
\hline 17.36 & 5 & N/A & N/A & N/A & N/A & N/A \\
\hline 6.076024405 & 0.291642262 & N/A & N/A & N/A & N/A & N/A \\
\hline
\end{tabular}

Therefore, we will obtain the following numerical data (Eq. 6):

Coefficients of regression: $\mathrm{a}_{0}=4.141839001 ; \mathrm{a}_{1}=6.46997 \times 10^{-6} ; \mathrm{a}_{0}=-$ $1.40348 \times 10^{-5} ; \quad \mathrm{a}_{3}=1.44834 \times 10^{-5} ; \quad \mathrm{a}_{4}=-0.000108872 ; \quad \mathrm{a}_{5}=1.58101 \times 10^{-5} ;$ $\mathrm{a}_{6}=3.12524 \times 10^{-5}$; coefficient of determination: $\mathrm{R}^{2}=0.9542$; calculated value of statistics $F=17.36$; quantity of observations $n=12$; quantity of the regression parameters with degrees of freedom of the denominator $p=7$; quantity of degrees of freedom of the denominator $p-1=6$; quantity of degrees of freedom of the numerator 
$\mathrm{n}-\mathrm{p}=5 ;$ root-mean-square deviations of the normal random variable $\varepsilon \mathrm{i}$ : $\mathrm{SE}_{\mathrm{y} 0}=1.01508043 ; \mathrm{SE}_{\mathrm{y} 1}=9.99331 \times 10^{-6} ; \mathrm{SE}_{\mathrm{y} 2}=6.99962 \times 10^{-6} ; \mathrm{SE}_{\mathrm{y} 3}=3.16138 \times 10^{-}$ 5; $\mathrm{SE}_{\mathrm{y} 4}=3.67525 \times 10^{-5} ; \mathrm{SE}_{\mathrm{y} 5}=4.87854 \times 10^{-6} ; \mathrm{SE}_{\mathrm{y} 6}=1.58577 \times 10^{-5} ;$ dispersion $\varepsilon$ : $\mathrm{SE}_{\mathrm{y} 2}=0.241512841$; sum of squares that is caused by regression: $\mathrm{SS}_{\text {regr }}=6.076024405$; residual sum of squares: $\mathrm{SS}_{\text {resid }}=0.291642262$.

Equation of regression will be written in the following form:

$$
\begin{aligned}
C_{C O}= & 4.141839001+6.46997 \times 10^{-6} x_{1}-1.40348 \times 10^{-5} x_{2}+1.44834 \times 10^{-5} x_{3}- \\
& -0.000108872 x_{4}+1.58101 \times 10^{-5} x_{5}+3.12524 \times 10^{-5} x_{6}
\end{aligned}
$$

Let us test meaningfulness of the coefficient of determination $\mathrm{R}^{2}$. Let us test it in accordance with the meaningfulness level $\alpha=0.05$. Let us find critical value with the help of tables of F-distribution with quantity of degrees of freedom $p-1=6$ and $n$ $\mathrm{p}=5$, that is, we will have $\mathrm{F}_{\text {crit }}=\mathrm{f}(0.05 ; 6 ; 5)=4.95$. We will obtain the calculated value $\mathrm{F}=17.36$. Let us compare it with the table critical value $\mathrm{F}_{\text {crit }}=\mathrm{f}(0.05 ; 6 ; 5)=4.95 \leq \mathrm{F}=17.36$, then $\mathrm{F}_{\text {crit }} \leq \mathrm{F}$ means that coefficient of determination $\mathrm{R}^{2}$ differs from zero substantially. Therefore, hypothesis $\mathrm{H}_{0}$ : $\mathrm{a}_{0}=\mathrm{a}_{1}=\mathrm{a}_{2}=\mathrm{a}_{3}=\mathrm{a}_{4}=\mathrm{a}_{5}=\mathrm{a}_{6}=0$ concerning absence of the regression dependence between variables $\mathrm{C}_{\mathrm{CO}}$ and $\mathrm{x}_{1}, \mathrm{x}_{2}, \mathrm{x}_{3}, \mathrm{x}_{4}, \mathrm{x}_{5}, \mathrm{x}_{6}$ is rejected because this fact does not comply with actual data of observations.

Let us estimate meaningfulness of the sample regression coefficients $a_{0}, a_{1}, a_{2}, a_{3}, a_{4}$, $a_{5}$, a6. Let us assume the following level of meaningfulness $\alpha=0.05$. Let us calculate the critical value of the Student distribution with $\mathrm{n}-\mathrm{p}=5$ degrees of freedom (of the order $\alpha / 2=0.025)$, that is, quantity $\mathrm{T}_{\text {crit }}=\mathrm{t}(0.025 ; 5)=2.57$. Let us use formula $t=\frac{a_{i}}{S E_{i}}$ and calculate value of statistics for all sample regression coefficients $a_{i}$. Results are presented in Table 3.

Table 3. Values of regression coefficients for $C O$

\begin{tabular}{c|c|c|c|c|c|c|c}
\hline $\mathrm{a}_{\mathrm{i}}$ & $\mathrm{a}_{0}$ & $\mathrm{a}_{1}$ & $\mathrm{a}_{2}$ & $\mathrm{a}_{3}$ & $\mathrm{a}_{4}$ & $\mathrm{a}_{5}$ & $\mathrm{a}_{6}$ \\
\hline $\mathrm{t}$ & 4.080306228 & 0.647429763 & -2.005075304 & 0.458135006 & -2.962295561 & 3.240750483 & 1.970797859 \\
\hline
\end{tabular}

Not all calculated values exceed their critical values in absolute magnitude. That is, these values are lesser for the coefficients $a_{1}, a_{2}, a_{3}$, and $a_{6}$, that is, the parameters, near which these coefficients stand (namely: quantity of the gasoline-powered passenger cars; quantity of the diesel-powered passenger cars; quantity of the gasoline-powered lorries, and quantity of the diesel-powered buses), do not have any essential influence upon the resulting parameter (upon the concentration of the carbon oxide $\mathrm{C}_{\mathrm{CO}}$ ) (Table 4).

Table 4. Nitrogen oxide $\left(\mathrm{NO}_{2}\right)$ (2017)

\begin{tabular}{c|c|c|c|c|c|c}
\hline$-2.10713 \times 10^{-6}$ & $1.10808 \times 10^{-7}$ & $-3.49816 \times 10^{-7}$ & $3.11257 \times 10^{-6}$ & $5.882 \times 10^{-7}$ & $-3.53302 \times 10^{-7}$ & 0.146914115 \\
\hline $4.71704 \times 10^{-7}$ & $2.3661 \times 10^{-7}$ & $7.27917 \times 10^{-8}$ & $5.48378 \times 10^{-7}$ & $1.0444 \times 10^{-7}$ & $1.49108 \times 10^{-7}$ & 0.015145818 \\
\hline N/A & 0.9146 & 0.003603566 & N/A & N/A & N/A & N/A \\
\hline N/A & 8.9263 & 5 & N/A & N/A & N/A & N/A \\
\hline N/A & 0.000695488 & $6.49284 \times 10^{-5}$ & N/A & N/A & N/A & N/A \\
\hline
\end{tabular}


Therefore, we will obtain the following numerical data (Eq. 7):

Coefficients of regression: $\mathrm{a}_{0}=0.146914115 ; \mathrm{a}_{1}=-3.53302 \times 10^{-7} ; \mathrm{a}_{2}=5.882 \times 10^{7}$; $\mathrm{a}_{3}=-2.10713 \times 10^{-6} ; \quad \mathrm{a}_{4}=3.11257 \times 10^{-6} ; \quad \mathrm{a}_{5}=-3.49816 \times 10^{-7} ; \quad \mathrm{a}_{6}=1.10808 \times 10^{-7} ;$ coefficient of determination: $R^{2}=0.9146$; calculated value of statistics $F=8.9263$; quantity of observations $n=12$; quantity of the regression parameters with degrees of freedom of the denominator $\mathrm{p}=7$; quantity of degrees of freedom of the denominator $p-1=6$; quantity of degrees of freedom of the numerator $n-p=5$; root-mean-square deviations of the normal random variable $\varepsilon \mathrm{i}$ : $\mathrm{SE}_{\mathrm{y} 0}=0.015145818$; $\mathrm{SE}_{\mathrm{y} 1}=1.49108 \times 10^{6} ; \mathrm{SE}_{\mathrm{y} 6}=2.3661 \times 10^{-7}$; dispersion $\varepsilon: \mathrm{SE}_{\mathrm{y} 2}=0.003603566 ;$ sum of squares that is caused by regression: $\mathrm{SS}_{\text {regr }}=0.000695488$; residual sum of squares: $\mathrm{SS}_{\text {resid }}=6.49284 \times 10^{-5}$.

Equation of regression will be written in the following form:

$$
\begin{aligned}
C_{N O 2}= & 0.146914115-3.53302 \times 10^{-7} x_{1}+5.882 \times 10^{-7} x_{2}-2.10713 \times 10^{-6} x_{3} \\
& +3.11257 \times 10^{-6} x_{4}-3.49816 \times 10^{-7} x_{5}+1.10808 \times 10^{-7} x_{6}
\end{aligned}
$$

Let us test meaningfulness of the coefficient of determination $\mathrm{R}^{2}$. Let us assume the following level of meaningfulness $\alpha=0.05$. Let us find critical value with the help of Table 4 of F-distribution with quantity of degrees of freedom $p-1=6$ and $n-p=5$ that is, we will have $F_{\text {crit }}=f(0.05 ; 6 ; 5)=4.95$. We will obtain the calculated value $F=8.9263$. Let us compare it with the table critical value $F_{\text {crit }}=f(0.05 ; 6 ; 5)=4.95 \leq F=8.9263$, then $\mathrm{F}_{\text {crit }} \leq \mathrm{F}$ means that coefficient of determination $\mathrm{R}^{2}$ differs from zero substantially. Therefore, hypothesis $\mathrm{H}_{0}: \mathrm{a}_{0}=\mathrm{a}_{1}=\mathrm{a}_{2}=\mathrm{a}_{3}=\mathrm{a}_{4}=\mathrm{a}_{5}=\mathrm{a}=0$ concerning absence of the regression dependence between variables $\mathrm{C}_{\mathrm{NO} 2}$ and $\mathrm{x}_{1}, \mathrm{x}_{2}, \mathrm{x}_{3}, \mathrm{x}_{4}, \mathrm{x}_{5}, \mathrm{x}_{6}$ is rejected because this fact does not comply with actual data of observations.

Let us estimate meaningfulness of the sample regression coefficients $a_{0}, a_{1}, a_{2}, a_{3}, a_{4}$, $\mathrm{a}_{5}$, a6. Let us assume the following level of meaningfulness $\alpha=0.05$. Let us calculate the critical value of the Student distribution with $n-p=5$ of degrees of freedom (of the order $\alpha / 2=0.025)$, that is, quantity $\mathrm{T}_{\text {crit }}=\mathrm{t}(0.025 ; 5)=2.57$. Let us use formula $t=\frac{a_{i}}{S E_{i}}$ and calculate value $S E_{i}$ of statistics for all sample regression coefficients $a_{i}$. Results are presented in Table 5.

Table 5. Values of regression coefficients for $\mathrm{NO}_{2}$

\begin{tabular}{c|c|c|c|c|c|c|c}
\hline $\mathrm{a}_{\mathrm{i}}$ & $\mathrm{a}_{0}$ & $\mathrm{a}_{1}$ & $\mathrm{a}_{2}$ & $\mathrm{a}_{3}$ & $\mathrm{a}_{4}$ & $\mathrm{a}_{5}$ & $\mathrm{a}_{6}$ \\
\hline $\mathrm{t}$ & 9.699978901 & -2.369433996 & 5.631947074 & -4.46706903 & 5.675968749 & -4.805713687 & 0.468313082 \\
\hline
\end{tabular}

Not all calculated values exceed their critical values in absolute magnitude. That is, these values are lesser for the coefficients $\mathrm{a}_{1}$ and $\mathrm{a}_{6}$, and parameters, near which they stand (namely: quantity of the gasoline-powered passenger cars and quantity of the diesel-powered buses), do not have any essential influence upon the resulting parameter (upon the concentration of the nitrogen dioxide $\left(\mathrm{NO}_{2}\right)$ ).

Therefore, we will obtain the following numerical data $(E q .8)$ :

Coefficients of regression: $\mathrm{a}_{0}=0.039613 ; \mathrm{a}_{1}=-2.03592 \times 10^{-7} ; \mathrm{a}_{2}=7.72122 \times 10^{-8}$; $a_{3}=-4.72374 \times 10^{-7} ; \quad a_{4}=3.05224 \times 10^{-7} ; \quad a_{5}=-1.68538 \times 10^{-8} ; \quad a_{6}=3.63821 \times 10^{-7} ;$ coefficient of determination: $R^{2}=0.9609$; calculated value of statistics $F=20.4988$; 
quantity of observations $n=12$; quantity of the regression parameters with degrees of freedom of the denominator $\mathrm{p}=7$; quantity of degrees of freedom of the denominator $p-1=6$; quantity of degrees of freedom of the numerator $n-p=5$; root-mean-square deviations of the normal random variable $\varepsilon \mathrm{i}: \mathrm{SE}_{\mathrm{y} 0}=0.006553 ; \mathrm{SE}_{\mathrm{y} 1}=6.45084 \times 10^{-8}$; $\mathrm{SE}_{\mathrm{y} 2}=4.51836 \times 10^{-8} ; \quad \mathrm{SE}_{\mathrm{y} 3}=2.04072 \times 10^{-7} ; \quad \mathrm{SE}_{\mathrm{y} 4}=2.37244 \times 10^{-7} ;$ $\mathrm{SE}_{\mathrm{y} 5}=3.14917 \times 10^{-8} ; \mathrm{SE}_{\mathrm{y} 6}=1.02364 \times 10^{-7}$; dispersion $\varepsilon: \mathrm{SE}_{\mathrm{y} 2}=0.001559004 ;$ sum of squares that is caused by regression: $\mathrm{SS}_{\text {regr }}=0.000298934$; residual sum of squares: $\mathrm{SS}_{\text {resid }}=1.21525 \times 10^{-5}$. Equation of regression will be written in the following form:

$$
\begin{aligned}
S O_{2}= & 0.039613-2.03592 \times 10^{-7} x_{1}+7.72122 \times 10^{-8} x_{2}-4.72374 \times 10^{-7} x_{3}+ \\
& +3.05224 \times 10^{-7} x_{4}-1.68538 \times 10^{-8} x_{5}+3.63821 \times 10^{-7} x_{6}
\end{aligned}
$$

Let us test meaningfulness of the coefficient of determination $\mathrm{R}^{2}$. Let us assume the following level of meaningfulness $\alpha=0.05$. Let us find critical value with the help of tables of F-distribution with quantity of degrees of freedom $p-1=6$ and $n-p=5$ that is, we will have $F_{\text {crit }}=f(0.05 ; 6 ; 5)=4.95$. We will obtain the calculated value $\mathrm{F}=20.4988$. Let us compare it with Table 6 critical value $F_{\text {crit }}=f(0.05 ; 6 ; 5)=4.95 \leq F=20.4988$, then $F_{\text {crit }} \leq F$ means that coefficient of determination $\mathrm{R}^{2}$ differs from zero substantially. Therefore, hypothesis $\mathrm{H}_{0}$ : $\mathrm{a}_{0}=\mathrm{a}_{1}=\mathrm{a}_{2}=\mathrm{a}_{3}=\mathrm{a}_{4}=\mathrm{a}_{5}=\mathrm{a}_{6}=0$ concerning absence of the regression dependence between variables $\mathrm{C}_{\mathrm{NO}}$ and $\mathrm{x}_{1}, \mathrm{x}_{2}, \mathrm{x}_{3}, \mathrm{x}_{4}, \mathrm{x}_{5}, \mathrm{x}_{6}$ is rejected because this fact does not comply with actual data of observations.

Table 6. Sulphur dioxide $\left(\mathrm{SO}_{2}\right)$

\begin{tabular}{c|c|c|c|c|c|c}
\hline $3.63821 \times 10^{-7}$ & $-1.68538 \times 10^{8}$ & $3.05224 \times 10^{7}$ & $-4.72374 \times 10^{-7}$ & $7.72122 \times 10^{-8}$ & $-2.03592 \times 10^{-7}$ & 0.039613 \\
\hline $1.02364 \times 10^{-7}$ & $3.14917 \times 10^{-8}$ & $2.37244 \times 10^{-7}$ & $2.04072 \times 10^{-7}$ & $4.51836 \times 10^{-8}$ & $6.45084 \times 10^{-8}$ & 0.006553 \\
\hline 0.96094 & 0.001559004 & N/A & N/A & N/A & N/A & N/A \\
\hline 20.4988 & 5 & N/A & N/A & N/A & N/A & N/A \\
\hline 0.000298934 & $1.21525 .10^{-5}$ & N/A & N/A & N/A & N/A & N/A \\
\hline
\end{tabular}

Let us estimate meaningfulness of the sample regression coefficients $a_{0}, a_{1}, a_{2}, a_{3}, a_{4}$, a5, a6. Let us assume the following level of meaningfulness $\alpha=0.05$. Let us calculate the critical value of the Student distribution with $n-p=5$ of degrees of freedom (of the order $\alpha / 2=0.025)$, that is, quantity $\mathrm{T}_{\text {crit }}=\mathrm{t}(0.025 ; 5)=2.57$. Let us use formula $t=\frac{a_{i}}{S E_{i}}$ and calculate value of statistics for all sample regression coefficients $\mathrm{a}_{\mathrm{i}}$ (Table 7).

Table 7. Values of regression coefficients for $\mathrm{SO}_{2}$

\begin{tabular}{c|c|c|c|c|c|c|c}
\hline $\mathrm{a}_{\mathrm{i}}$ & $\mathrm{a}_{0}$ & $\mathrm{a}_{1}$ & $\mathrm{a}_{2}$ & $\mathrm{a}_{3}$ & $\mathrm{a}_{4}$ & $\mathrm{a}_{5}$ & $\mathrm{a}_{6}$ \\
\hline $\mathrm{t}$ & 6.045499 & -3.156060558 & 1.708852297 & -2.314738779 & 1.2865452 & -0.535182576 & 3.554182534 \\
\hline
\end{tabular}

Not all calculated values exceed their critical values in absolute magnitude. That is, these values are lesser for the coefficients $\mathrm{a}_{2}, \mathrm{a}_{3}, \mathrm{a}_{4}$ and $\mathrm{a}_{6}$, and parameters, near which they stand (namely: quantity of the diesel-powered passenger cars, quantity of the 
gasoline-powered lorries, quantity of the diesel-powered lorries, and quantity of the diesel-powered buses), do not have any essential influence upon the resulting parameter (upon the concentration of the sulphur dioxide $\mathrm{SO}_{2}$ ).

Therefore, we will obtain the following numerical data (Eq. 9):

Coefficients of regression: $\mathrm{a}_{0}=0.031884 ; \mathrm{a}_{1}=2.2113 \times 10^{-7} ; \mathrm{a}_{2}=2.12811 \times 10^{-7}$; $\mathrm{a}_{3}=-7.6196 \times 10^{-7} ; \quad \mathrm{a}_{4}=1.99258 \times 10^{-6} ; \quad \mathrm{a}_{5}=-2.02801 \times 10^{-7} ; \quad \mathrm{a}_{6}=-3.85243 \times 10^{-7} ;$ coefficient of determination: $R^{2}=0.9745$; calculated value of statistics $F=31.8623$; quantity of observations $n=12$; quantity of the regression parameters with degrees of freedom of the denominator $\mathrm{p}=7$; quantity of degrees of freedom of the denominator $\mathrm{p}-1=6$; quantity of degrees of freedom of the numerator $\mathrm{n}-\mathrm{p}=5$; root-mean-square deviations of the normal random variable $\varepsilon \mathrm{i}: \mathrm{SE}_{\mathrm{y} 0}=0.009114 ; \mathrm{SE}_{\mathrm{y} 1}=8.97233 \times 10^{-8}$; $\mathrm{SE}_{\mathrm{y} 2}=6.28449 \times 10^{-8} ; \quad \mathrm{SE}_{\mathrm{y} 3}=2.8384 \times 10^{-7} ; \quad \mathrm{SE}_{\mathrm{y} 4}=3.29977 \times 10^{-7} ;$ $\mathrm{SE}_{\mathrm{y} 5}=4.38011 \times 10^{-8} ; \mathrm{SE}_{\mathrm{y} 6}=1.42376 \times 10^{-7}$; dispersion $\varepsilon: \mathrm{SE}_{\mathrm{y} 2}=0.002168383 ;$ sum of squares that is caused by regression: $\mathrm{SS}_{\text {regr }}=0.000898877$; residual sum of squares: $\mathrm{SS}_{\text {resid }}=2.35094 \times 10^{-5}$. Equation of regression will be written in the following form:

$$
\begin{aligned}
C_{C H}= & 0.031884+2.2113 \times 10^{-7} x_{1}+2.12811 \times 10^{-7} x_{2}-7.6196 \times 10^{-7} x_{3}+ \\
& +1.99258 \times 10^{-6} x_{4}-2.02801 \times 10^{-7} x_{5}-3.85243 \times 10^{-7} x_{6}
\end{aligned}
$$

Let us test meaningfulness of the coefficient of determination $\mathrm{R}^{2}$. Let us assume the following level of meaningfulness $\alpha=0.05$ Let us find critical value with the help of Table 8 of F-distribution with quantity of degrees of freedom $\mathrm{p}-1=6$ and $\mathrm{n}-\mathrm{p}=5$ that is, we will have $F_{\text {crit }}=\mathrm{f}(0.05 ; 6 ; 5)=4.95$. We will obtain the calculated value $\mathrm{F}=31.8623$. Let us compare it with Table 9 critical value $F_{\text {crit }}=f(0.05 ; 6 ; 5)=4.95 \leq \mathrm{F}=31.8623$, that is, $F_{\text {crit }} \leq \mathrm{F}$ means that coefficient of determination $\mathrm{R}^{2}$ differs from zero substantially. Therefore, hypothesis $\mathrm{H}_{0}$ : $\mathrm{a}_{0}=\mathrm{a}_{1}=\mathrm{a}_{2}=\mathrm{a}_{3}=\mathrm{a}_{4}=\mathrm{a}_{5}=\mathrm{a}_{6}=0$ concerning absence of the regression dependence between variables $\mathrm{C}_{\mathrm{CH}}$ and $\mathrm{x}_{1}, \mathrm{x}_{2}, \mathrm{x}_{3}, \mathrm{x}_{4}, \mathrm{x}_{5}, \mathrm{x}_{6}$ is rejected because this fact does not comply with actual data of observations.

Table 8. Hydrocarbons (CH)

\begin{tabular}{c|c|c|c|c|c|c}
\hline$-3.85243 \times 10^{7}$ & 0.031884 & $-2.02801 \times 10^{7}$ & $1.99258 \times 10^{6}$ & $-7.6196 \times 10^{7}$ & $2.12811 \times 10^{-7}$ & $2.2113 \times 10^{-7}$ \\
\hline $1.42376 \times 10^{-7}$ & 0.009114 & $4.38011 \times 10^{-8}$ & $3.29977 \times 10^{-7}$ & $2.8384 \times 10^{7}$ & $6.28449 \times 10^{-8}$ & $8.97233 \times 10^{-8}$ \\
\hline 0.9745 & N/A & 0.002168383 & N/A & N/A & N/A & N/A \\
\hline 31.8623 & N/A & 5 & N/A & N/A & N/A & N/A \\
\hline 0.000898877 & N/A & $2.3509410^{-5}$ & N/A & N/A & N/A & N/A \\
\hline
\end{tabular}

Let us estimate meaningfulness of the sample regression coefficients $a_{0}, a_{1}, a_{2}, a_{3}, a_{4}$, a5, a6. Let us assume the following level of meaningfulness $\alpha=0.05$. Let us calculate the critical value of the Student distribution with $n-p=5$ of degrees of freedom (of the order $\alpha / 2=0.025)$, that is, quantity $\mathrm{T}_{\text {crit }}=\mathrm{t}(0.025 ; 5)=2.57$. Let us use formula $t=\frac{a_{i}}{S E_{i}}$ and calculate value of statistics for all sample regression coefficients $a_{i}$ (Table 9).

The calculated values exceed their critical values in absolute magnitude, that is, all coefficients have essential influence upon the resulting parameter (concentration of hydrocarbons $(\mathrm{CH})$ ). In order to ensure formal characterization and development of the 
sustainability, it is necessary to define the model of correlation not only in respect of the ecological traffic safety, but also in respect of the possibilities for connection of the ecological safety parameters with the road traffic safety.

Table 9. Values of regression coefficients for hydrocarbons $(\mathrm{CH})$

\begin{tabular}{c|c|c|c|c|c|c|c}
\hline $\mathrm{a}_{\mathrm{i}}$ & $\mathrm{a}_{0}$ & $\mathrm{a}_{1}$ & $\mathrm{a}_{2}$ & $\mathrm{a}_{3}$ & $\mathrm{a}_{4}$ & $\mathrm{a}_{5}$ & $\mathrm{a}_{6}$ \\
\hline $\mathrm{t}$ & 3.498505 & 2.464577608 & 3.386289809 & -2.684472656 & 6.038556981 & -4.630032638 & -2.705815029 \\
\hline
\end{tabular}

\section{Influence of the road conditions upon the traffic safety}

In accordance with the traffic terminology, "road conditions" term is meant as the totality of geometrical parameters, road service qualities of roads, road pavements, and components of the engineering equipment, which have direct influence upon conditions of traffic (performance of relevant operations by drivers in the course of transportation of passengers and freight).

The above definition does not describe interconnections between the road conditions and traffic safety. At the same time, road conditions (which are the constant component of the complex system - "road conditions-transport flows-environment") have positive or negative influence upon the traffic safety in accordance with the quality state of the road conditions. Therefore, it is necessary to define this term more exactly and we will interpret road conditions as the totality of those factors, which have positive or negative influence upon the road traffic safety of transportation facilities and pedestrians. Such road factors include all the factors that exist on the roads except for the traffic participants and environment conditions.

It is worthy of note that road conditions are not constant/stationary ones in respect of a driver in the course of traffic: they are not changing all the time in themselves, they are changing in a driver's perception in the course of traffic. If a vehicle moves with the speed of $90 \mathrm{~km} / \mathrm{h}(25 \mathrm{~m} / \mathrm{s}$ ), components of road conditions (road signs, guideposts, delineators, traffic dividers), bridges, pedestrian crossings, road intersections, and so on occur and change during several seconds only. During a short period of time, a driver acquires information, analyses it, makes a decision, and performs this decision. In the course of a time, the driver forgets previous information because he/she acquires new information without interruptions.

It is possible to reveal direct influence of the road conditions upon the traffic safety with the help of analysis of the actual mileage distribution of road traffic accidents (RTA) in respect of the road length.

If RTAs are uniformly distributed (without any obvious aggregations) over the length of the road sections that are analysed, then road conditions comply with the requirements of the traffic, which was organised in one way or another, and it is possible to describe these road conditions as the conditions that are supportive to the road traffic safety. If road conditions on a certain road section do not comply with the traffic safety requirements, and there exists an aggregation (concentration) of the RTAs, this fact suggests that there is a negative influence of one road factor or several road factors upon the road traffic safety. In order to ensure the road traffic safety of the onthe-road vehicles and pedestrians on the motor roads in operation, we have to analyse various factors of the road conditions $(\mathrm{Dj})$. 
Only strictly determined factors of the road conditions can be treated as the road conditions of a specific road section.

For example, the following factors can be treated as the road conditions of the onelevel interchange with the jughandle left turns: vertical and horizontal road markings of the traffic way, metal traffic dividers, stopping lanes on the shoulders of roads, non-skid properties and friction factor of the traffic way, as well as road signs.

It is possible to describe the entire assembly of the specific road factors (complex of the road factors $\left.\left(K_{d}\right)\right)$, which are necessary in order to ensure the road traffic safety, with the help of the following formula (Eq. 10):

$$
\begin{gathered}
K_{d}=\left\{D_{1}, D_{2}, \ldots, D_{j}, \ldots, D_{k}\right\} \\
j=\overline{1, h}
\end{gathered}
$$

where $\mathrm{K}_{\mathrm{d}}$ - complex of the road factors, which are conductive to the road traffic safety; $\mathrm{Dj}$ - j-th road factor, which has influence upon the road traffic safety.

Let us connect each specific road factor $(\mathrm{Dj})$ with relevant probabilistic event $(\mathrm{Aj})$ and vice versa (Eq. 11):

$$
\begin{gathered}
D_{j} \leftrightarrow A_{j} \\
j=\overline{1, h}
\end{gathered}
$$

then Equation 10 (taking into account Eq. 11) will be written in the following form (Eq. 12):

$$
K_{d}=\left\{A_{1}, A_{2}, \ldots, A_{j}, \ldots, A_{k}\right\}
$$

where $A_{j}-j$-th probabilistic event, which corresponds to $(\mathrm{Dj})$ road factor.

We will treat a specific road factor on the specific section of a road as the probabilistic event in respect of the road conditions. For example, availability of the road markings of the traffic way, specific road sign, and the speed change lane, that is, availability of the specific kinds of the installed road elements, which are conductive to the road traffic safety.

We will treat each specific section of the roads in operation as the probabilistic object with probabilistic factors. In accordance with the probabilistic point of view, we will understand "observation" as the analysis of the mileage distributions of the RTAs, as well as analysis of the road conditions over the specific sections of the motor roads in operation. Certain road conditions (such as physical reality, for example) contain the probabilistic essence, which is an imperceptible one for a driver in the course of traffic and which is connected with the improvidence of the pre-determined change in the existing road conditions, elements of roads, quality state of roads, in the geometrical dimensions in plan view, as well as in the longitudinal and cross profiles.

In the course of traffic, driver does not estimate length of the straightforward or curved sections, radiuses of bends in plan view and in the longitudinal profile, clear vision distance of the road surface, sight distance to the on-coming motor vehicle, he/she does not estimate width of the traffic way, width of the traffic lanes, tire-to- 
surface friction coefficient of the road pavement, road pavement smoothness and all the rest circumstances. It is this factor that can become the direct or indirect reason of occurrence of the error, which results in the incorrect selection of the traffic condition by the driver in the case of occurrence of a conflict situation that is transformed into an emergency situation and results in occurrence of the RTA.

In the connection with the above-stated conclusions, one may state that there is a necessity in the permanent and targeted monitoring over the state of the road conditions. It is possible to perform such monitoring with the help of results of investigations and analysis of actual distributions of the RTA within the one-level road junctions, including road junctions with the jughandle left turns. Development of the prognostic stochastic models makes it possible to ensure operational finding the places or sections of possible occurrence of various RTAs, estimate existing conditions, and prevent accidents within these sections through the object-oriented improvement of the road conditions, which include the entire complex of interventions into relevant factors, as well as influence upon the traffic flow modes.

As concerns practice of the operational maintenance of roads, the road traffic safety is in direct dependence on the quality state of the road conditions because this state is one of the controllable components of the entire system.

\section{Road junctions impact on the environment}

The most difficult conditions for traffic of the transportation facilities occur on the motor roads junctions (Bevrani and Chung, 2012). These road junctions determine traffic capacity of the entire network, and they have influence upon the density and speed of traffic (Cao et al., 2016). Road junctions are the places, where one can always wait for occurrence of traffic congestions, increased risk of accidents, as well as growth of the emission rate of harmful components by motor engines to the environment (Yue et al., 2016).

Road junctions (highway crossings and road junctions) of motor roads are usually designed and constructed in one level or in several levels (Ghahramani and Hemmatyar, 2017). The one-level road junctions are the most dangerous ones. Intensity of traffic on any highway crossing is equal to the sum of intensities on the roads, which joint to the highway (Chaudhary et al., 2017). Therefore, motor roads near a highway crossing have greater loads as compared with other road sections (Cacciabue, 2018). Turns of certain motor vehicles from the right side and (particularly) from the left side create obstacles for traffic of those transportation facilities, which go without changes in the traffic direction (Lo and Tsai, 2009).

As concerns the one-level road junctions, there occur points of crossing, branching, as well as points of influence of the traffic trajectories of the transportation facilities (Tian et al., 2018). A simple four-side highway crossing includes 16 highway crossing points, 8 branching points, and 8 points of influence (Nagler and Ward, 2016). Such points are called the conflict points (Mendoza, 2017). The higher traffic intensity and the greater share of the transportation facilities, which make right and particularly left turns, the higher danger of occurrence of traffic congestions, which ensure growth of the increased pollution of the environment by the components, which are discharged along with the exhaust gases, as well as which ensure propagation of noise and vibrations (Wattana and Nishio, 2017).

As concerns the channelized road junctions, width of the traffic lane on the main road is determined at the level of $3.75 \mathrm{~m}$ (Bartoková et al., 2015). The least length of 
such lane in both sides from an interchange on the main road is equal to $150 \mathrm{~m}$ if traffic intensity does not exceed 2,000 vehicle/day; $200 \mathrm{~m}$ if traffic intensity is equal to from 2,000 to 3,000 vehicle/day; $500 \mathrm{~m}$ if traffic intensity is equal to from 3,000 to 4,000 vehicle/day, and $900 \mathrm{~m}$ if traffic intensity is more than 4,000 vehicle/day. Width of the traffic lane of the secondary highways at the distance of no lesser than $50 \mathrm{~m}$ in both sides from an interchange is determined at the level of no lesser than $7 \mathrm{~m}$ for all categories of motor vehicles on the two-lane road. Width of the traffic lane on the ramps/exits of the channelized road junctions is determined at the level of from 4 to $5.8 \mathrm{~m}$ depending on the ramp/exit radius, which must be no lesser than $10 \mathrm{~m}$ (FISITA, 2011). It is also necessary to strengthen shoulders within the road junctions, while their width is to be defined at the level of $3.75 \mathrm{~m}$ for the main road and at the level of $2.5 \mathrm{~m}$ for the secondary road. At the same time, it is necessary to construct special speed change lanes (overtaking lanes) being no lesser than $3.75 \mathrm{~m}$ in width at all channelized and partially channelized one-level road junctions. It is recommended to design channelized road junctions at the summary consolidated traffic intensity from 2,000 to 8,000 consolidated transportation facilities per day (Duduta, 2015).

It is also recommended to design roundabout (traffic circle) one-level road junctions in the cases, if traffic intensities on the roads, which cross each other, are the same or if difference between these intensities does not exceed $20 \%$, while quantity of flows of motor vehicles within the left-turn flows is equal to no lesser than $40 \%$ on both roads. A roundabout (circle) intersection with a big radius of the centre (rotary) island is the most dangerous one as compared with all other kinds of one-level road junctions. All manoeuvres of the transportation facilities on the roundabout road junctions are restricted to inclusion of motor vehicles into the traffic flow and subsequent exit from the flow (traffic convergence and divergence). Therefore, there exist interlacing of flows on the roundabout road junctions, but there are no any highway crossings. However, big quantity of interlacements of the traffic trajectories of the transportation facilities causes decrease of speed as compared with the speed on the approach roads. In addition, great areas are required for construction of the roundabout intersections. The one-level road junctions result in decrease of the traffic speed and traffic capacity of a road, as well as they cause growth of quantity of the road traffic accidents.

The authors have compaired the results, which were obtained in 2018, with relevant results for 2017 (the year, when organisation of traffic was changed). It is possible to state the following: quantity of harmful emissions (carbon oxides (CO), nitrogen dioxide $\left(\mathrm{NO}_{2}\right)$, sulphur dioxide $\left(\mathrm{SO}_{2}\right)$, and hydrocarbons $(\mathrm{CH})$ ) has decreased at the expense of the changes in the traffic organisation within relevant road intersection, as well as at the expense of decrease in the standing time of motor vehicles on the road intersection, and these factors have caused decrease of emissions of relevant gases. It is obvious from the investigation results that quantity of the gasoline-powered and dieselpowered buses has the biggest influence upon concentration of harmful emissions (this is the case for all groups of harmful emissions). Diesel-powered buses and lorries have essential influence upon emissions of the nitrogen dioxide $\left(\mathrm{NO}_{2}\right)$. High value of the correlation coefficient (within the limits from 0.88 to 0.97 ) confirms the great strength of interconnection between relevant variables. 


\section{Conclusions}

Through analyzing the obtained results, it is possible to make the following conclusions:

1. Quantity of the diesel-powered lorries and quantity of the gasoline-powered buses (respectively) have the biggest influence upon concentration of the polluting substances in the atmospheric air. The diesel-powered passenger cars and diesel-powered lorries have somewhat less influence, while quantity of the gasoline-powered buses has almost insufficient influence upon concentration of the polluting substances.

2. All groups of motor vehicles have essential influence on hydrocarbons. The gasoline-powered buses have essential influence on the concentration of the carbon oxides (CO), while diesel-powered buses and lorries have influence on the concentration of the nitrogen dioxide $\left(\mathrm{NO}_{2}\right)$.

3. Not all calculated values exceed their critical values in absolute magnitude. That is, these values are lesser for the coefficients $a_{2}, a_{3}, a_{5}, a_{6}$, that is, the parameters, near which they stand, do not have any essential influence upon the resulting parameter (upon the concentration of the carbon oxides and concentration of hydrocarbons $(\mathrm{CH})$ ). Only quantity of the gasoline-powered passenger cars has essential influence upon this component of the atmosphere pollution, while quantity of the diesel-powered passenger cars has somewhat less influence in respect of this factor.

4. Having analysed the results obtained, the authors have proposed the following changes in organisation of the traffic on the road intersection under consideration: partial traffic decrease at the expense of organisation of the jughandle right turn and installation of additional sections of the traffic light. It was found that quantity of harmful emissions (carbon oxides $(\mathrm{CO})$, nitrogen dioxide $\left(\mathrm{NO}_{2}\right)$, sulphur dioxide $\left(\mathrm{SO}_{2}\right)$, and hydrocarbons $(\mathrm{CH})$ ) has decreased at the expense of the changes in the traffic organisation within relevant road intersection, as well as at the expense of decrease in the standing time of motor vehicles on the road intersection, and these factors have caused decrease of emissions of relevant gases.

5. It was found that the development of the prognostic stochastic models makes it possible to ensure operational finding the places or sections of possible occurrence of various RTAs, estimate existing conditions, and prevent accidents within these sections through the object-oriented improvement of the road conditions, which include the entire complex of interventions into relevant factors, as well as influence upon the traffic flow modes.

6. The analysis of the drivers' specific features of perception of the road conditions let us to make the conclusion in respect of the fact that we must treat road conditions as the dangerous ones in the situations, where the sudden change in the traffic modes of the transportation facilities occurs as compared with the previous conditions and when drivers must work with the increased attention. These road conditions cause occurrence of the road traffic situations, which transform into accidents, and the RTA aggregation is observed.

\section{REFERENCES}

[1] Bartoková, I., Andreas, B., Juraj, B., Gera, M. (2015): Fog prediction for road traffic safety in a coastal desert region: improvement of nowcasting skills by the machinelearning approach. - Boundary-Layer Meteorology 157(3): 501-516. https://doi.org/10.1007/s10546-015-0069-x. 
[2] Bevrani, K., Chung, E. (2012): An examination of the microscopic simulation models to identify traffic safety indicators. - International Journal of Intelligent Transportation Systems Research 10(2): 66-81. https://doi.org/10.1007/s13177-011-0042-0.

[3] Cacciabue, P. C. (2018): Book review on cognitive engineering and safety organization in air traffic management. - Cognition, Technology \& Work. https://doi.org/10.1007/s10111-018-0532-9.

[4] Cao, Y., Yang, Z. Z., Zuo, Z. Y. (2016): The effect of curb parking on road capacity and traffic safety. - European Transport Research Review 9(1): 4. https://doi.org/10.1007/s12544-016-0219-3.

[5] Chang, B.-J., Liang, Y.-H., Yang, H.-J. (2014): Performance analysis with traffic accident for cooperative active safety driving in VANET/ITS. - Wireless Personal Communications 74(2): 731-755. https://doi.org/10.1007/s11277-013-1318-2.

[6] Chang, I. (2011): The analysis of safety impacts of "near-site" traffic signals. - KSCE Journal of Civil Engineering 15(7): 1285. https://doi.org/10.1007/s12205-011-1343-1.

[7] Chaudhary, A., Klette, R., Raheja, J. L., Jin, X. (2017): Introduction to the special issue on computer vision in road safety and intelligent traffic. - EURASIP Journal on Image and Video Processing 2017(1): 16. https://doi.org/10.1186/s13640-017-0166-5.

[8] Duduta, N. (2015): Traffic safety in surface public transport systems: a synthesis of research. - Public Transport 7(2): 121-137. https://doi.org/10.1007/s12469-014-0087-y.

[9] Ghahramani, S. A. A. G., Hemmatyar, A. M. A. (2017): A hybrid approach to analyze the impact of vehicular traffic on performance of $802.11 \mathrm{p}$ protocol for safety communications in vehicular ad hoc networks: a quantitative analysis. - Wireless Personal Communications 97(3): 4493-4528. https://doi.org/10.1007/s11277-017-4735-9.

[10] Goniewicz, K., Goniewicz, M., Pawłowski, W., Fiedor, P. (2016): Road accident rates: strategies and programmes for improving road traffic safety. - European Journal of Trauma and Emergency Surgery 42(4): 433-438. https://doi.org/10.1007/s00068-0150544-6.

[11] Kureckova, V. (2017): First aid as an important traffic safety factor - evaluation of the experience-based training. - European Transport Research Review 9(1): 5. https://doi.org/10.1007/s12544-016-0218-4.

[12] Lo, N.-W., Tsai, H.-C. (2009): A reputation system for traffic safety event on vehicular ad hoc networks. - EURASIP Journal on Wireless Communications and Networking 2009(1): 125348. https://doi.org/10.1155/2009/125348.

[13] Marisamynathan, S., Vedagiri, P. (2018): Estimation of pedestrian safety index value at signalized intersections under mixed traffic conditions. - Transportation in Developing Economies 4(1): 5. https://doi.org/10.1007/s40890-018-0058-0.

[14] Mendoza, A. E. (2017): The worldwide approach to Vision Zero: implementing road safety strategies to eliminate traffic-related fatalities. - Current Trauma Reports 3(2): 104-110. https://doi.org/10.1007/s40719-017-0085-z.

[15] Nagler, M. G., Ward, N. J. (2016): Lonely highways: the role of social capital in rural traffic safety. - Eastern Economic Journal 42(1): 135-156. https://doi.org/10.1057/eej.2014.60.

[16] Svensson, T., Summerton, J., Hrelja, R. (2014): The politics of speed - local and regional actors' views on speed limits, traffic safety and mobility in Sweden. - European Transport Research Review 6(1): 43-50. https://doi.org/10.1007/s12544-013-0109-x.

[17] Tian, L., Jiang, J., Tian, L. (2018): Safety analysis of traffic flow characteristics of highway tunnel based on artificial intelligence flow net algorithm. - Cluster Computing. https://doi.org/10.1007/s10586-017-1340-3.

[18] Wattana, K., Nishio, M. (2017): Application of a regression model for predicting traffic volume from dynamic monitoring data to the bridge safety evaluation. - Journal of Civil Structural Health Monitoring 7(4): 429-443. https://doi.org/10.1007/s13349-017-0234-7. 
[19] Yue, Y., Luo, S., Luo, T. (2016): Micro-simulation model of two-lane freeway vehicles for obtaining traffic flow characteristics including safety condition. - Journal of Modern Transportation 24(3): 187-195. https://doi.org/10.1007/s40534-016-0103-9.

[20] FISITA (2011): Second FISITA world automotive summit tackles global traffic safety. ATZautotechnology 11(1): 6-7. https://doi.org/10.1365/s35595-011-0003-x. 